\title{
OPTIMALISASI KEUNTUNGAN PADA PERUSAHAAN KERIPIK BALADO MAHKOTA DENGAN METODE SIMPLEKS
}

\author{
Muhammad Muzakki \\ Program Studi Matematika, \\ Fakultas Matematika dan Ilmu Pengetahuan Alam, Universitas Andalas Padang, \\ Kampus UNAND Limau Manis Padang 25163, Indonesia \\ MuhammadMuzakki72@yahoo.com
}

\begin{abstract}
Abstrak. Mendapatkan keuntungan besar adalah tujuan utama dalam setiap bisnis. Jadi, perusahaan memerlukan perhitungan pemrograman linier metode simpleks untuk menghasilkan produk dengan penggunaan sumber daya maksimal untuk memberikan keuntungan yang optimal. Perusahaan juga harus memperhatikan setiap perubahan yang terjadi, baik dari keuntungan atau sumber daya agar tidak mempengaruhi keuntungan optimal perusahaan. Tujuan dari penulisan ini adalah untuk mencari keuntungan optimal yang diperoleh perusahaan Keripik Balado Mahkota dari memproduksi keripik balado. Dari hasil penelitian dan berdasarkan perhitungan dari pemrograman linier metode simpleks, keuntungan optimal diperoleh perusahaan Keripik Balado Mahkota apabila memproduksi keripik balado bulat $\frac{1}{2} \mathrm{~kg}$ sebanyak 278 bungkus dan keripik panjang $\frac{1}{2} \mathrm{~kg}$ sebanyak 412 bungkus dengan keuntungan maksimal adalah Rp. 5.187.596, - untuk setiap kegiatan produksi per-hari. Dalam uji sensitivitas perubahan masih bisa ditolerir tanpa mengubah keuntungan optimal dengan melakukan perubahan yang sesuai atau berada di kisaran perubahan yang ada dalam analisis sensitivitas.

Kata kunci: Pemrograman Linier, Metode Simpleks, Analisis sensitivitas,Perusahaan Keripik Balado Mahkota.
\end{abstract}

\section{Pendahuluan}

Perusahaan Keripik Balado Mahkota bergerak di bidang usaha keripik yang memproduksi lebih dari satu produk yaitu keripik balado, cincang dan sanjai. Perusahaan memiliki visi yaitu menjadikan perusahaan ini sebagai perusahaan terkemuka dalam memproduksi makanan spesifik dan pengerak perekonomian di Sumatera Barat. Keripik balado merupakan produk utama dari perusahaan. Oleh karena itu untuk memproduksi keripik balado ini memiliki keterbatasan atas sumber dayanya, baik keterbatasan dalam jumlah bahan baku, mesin, peralatan, ruang, tenaga kerja, ataupun jam kerja. Dengan keterbatasan ini perusahaan perlu merencanakan suatu strategi agar semua sumber daya yang ada dalam perusahaan digunakan atau dialokasikan secara tepat dan optimal sehingga dapat menghasilkan kombinasi output yang memberikan keuntungan maksimal. Berdasarkan keterangan di atas, diperlukan suatu metode dalam mengetahui dengan tepat penggunaan sumber daya perusahaan serta kombinasi dari produk yang dihasilkan. Untuk mengatasi hal ini dapat digunakan pemecahan masalah dengan menggunakan pemrograman linear dengan metode simpleks. Dari uraian di atas, dan didorong oleh keingintahuan untuk mengetahui 
pemograman linier khususnya metode simpleks dalam menyelesaikan permasalahan optimalisasi keuntungan pada Keripik Balado Mahkota.

\section{Landasan Teori}

\subsection{Beberapa Konsep Dasar}

Ada beberapa konsep dasar yang sangat sering digunakan dalam pemrograman linier metode simpleks untuk menentukan solusi optimal simpleks, didasarkan pada teknik eleminasi Gauss Jordan adalah sebagai berikut :

Definisi 1. Variabel keputusan adalah variabel yang menguraikan secara lengkap keputusan yang akan dibuat[1].

Definisi 2. Fungsi tujuan adalah fungsi linier dari variabel keputusan yang akan dimaksimalkan contohnya untuk pendapatan keuntungan atau diminimalkan contohnya untuk biaya produksi [1].

Definisi 3. Fungsi kendala adalah pembatas atas sumber daya yang tersedia dan permintaan atas sumber daya yang ada[1].

Definisi 4. Iterasi adalah tahapan perhitungan dimana nilai dalam perhitungan itu tergantung dari nilai tabel sebelumnya[1].

Definisi 5. Nilai Kanan (NK) adalah nilai kanan persamaan yaitu merupakan nilai sumber daya pembatas yang masih tersedia[1].

Definisi 6. Variabel basis adalah variabel yang nilainya bukan nol pada sembarang iterasi. Pada solusi awal, variabel basis merupakan variabel slack (jika fungsi kendala merupakan pertidaksamaan $\leq$ ) atau variabel artificial (jika fungsi kendala menggunakan pertidaksamaan geq atau $=$ ). Secara umum, jumlah variabel basis selalu sama dengan jumlah fungsi kendala[1].

Definisi 7. Variabel slack adalah variabel yang ditambahkan ke model matematik kendala untuk mengkonversikan pertidaksamaan $\leq$ menjadi persamaan $=$ [1].

Definisi 8. Variabel surplus adalah variabel yang dikurangkan dari model matematik kendala untuk mengkonversikan pertidaksamaan $\geq$ menjadi persamaan $=$ [1].

Definisi 9. Variabel artificial adalah variabel yang ditambahkan ke model matematik kendala dengan bentuk $(\geq)$ atau $(=)$ untuk difungsikan sebagai variabel basis awal[1].

\subsection{Pemrograman Linear}

Pemrograman linier merupakan bagian dari riset operasional. Riset operasional adalah proses pencarian cara untuk menentukan tindakan yang terbaik atau optimal dari suatu pengambilan keputusan dalam situasi sumber-sumber daya yang terbatas [2].

Suatu pernyataan secara matematik dalam bentuk umum dari pemrograman linier adalah sebagai berikut: Tentukan $x_{1}, x_{2},, x_{n}$ yang memaksimalkan fungsi linier 


$$
Z=C_{1} x_{1}+C_{2} x_{2}+.+C_{n} x_{n}
$$

di bawah kendala-kendala

$$
\begin{aligned}
& a_{11} x_{1}+a_{12} x_{2}+. .+a_{1 n} x_{n} \leq b_{1} \\
& a_{21} x_{1}+a_{22} x_{2}+. .+a_{2 n} x_{n} \leq b_{2} \\
& \ldots \\
& a_{m 1} x_{1}+a_{m 2} x_{2}+. .+a_{m n} x_{n} \leq b_{m} \\
& \text { dimana } x_{1}, x_{2},, x_{n} \geq 0 \\
& \text { untuk } C_{1}, C_{2},, C_{n}, a_{11}, a_{12},, a_{m n} \text { dan } b_{1}, b_{2},, b_{m} \text { adalah konstanta yang diten- } \\
& \text { kan. } \\
& \text { Keterangan: } C_{n}=\text { nilai koefisien keuntungan per-bungkus produk untuk se- } \\
& \text { p } x_{n} \\
& x_{n}=\text { variabel keputusan ke- } n \\
& a_{(m n)}=\text { kebutuhan sumber daya } m \text { untuk setiap } x_{n} \\
& b_{m}=\text { jumlah sumber daya yang tersedia } \\
& n=\text { banyaknya variabel keputusan mulai dari } 1,2,, \mathrm{n} \\
& m=\text { banyaknya jenis sumber daya yang digunakan mulai dari } 1,2,, \mathrm{~m}
\end{aligned}
$$
tukan. tiap $x_{n}$

\subsection{Metode Simpleks}

Pada tahun 1947 George B. Dantzig memperkenalkan suatu metode yang disebut metode simpleks, yaitu sebuah metode yang digunakan untuk menyelesaikan masalah pemrograman linier dengan banyak variabel. Metode simpleks adalah suatu prosedur aljabar yang melalui serangkaian operasi-operasi berulang, dapat memecahkan masalah yang terdiri dari 2 variabel atau lebih [3].

Setelah mengetahui cara pengubahan bentuk umum pemrograman linier ke dalam bentuk baku. Langkah berikutnya adalah langkah awal penyelesaian dengan metode simpleks, yaitu pembuatan tabel awal simpleks yang memuat solusi awal dari masalah yang ingin diselesaikan, secara umum tabel awal simpleks dapat dilihat lihat pada Tabel 1

\begin{tabular}{|c|c|c|c|c|c|c|c|c|c|c|}
\hline$V b$ & $Z$ & $x_{1}$ & $x_{2}$ & $\ldots$ & $x_{n}$ & $S_{1}$ & $S_{2}$ & $\ldots$ & $S_{n}$ & $N K$ \\
\hline$Z$ & 1 & $-C_{1}$ & $-C 2$ & $\ldots$ & $-C n$ & 0 & 0 & $\ldots$ & 0 & 0 \\
\hline$S_{1}$ & 0 & $a_{11}$ & $a_{12}$ & $\ldots$ & $a_{1 n}$ & 1 & 0 & $\ldots$ & 0 & $b_{1}$ \\
\hline$S_{2}$ & 0 & $a_{21}$ & $a_{22}$ & $\ldots$ & $a 2 n$ & 0 & 1 & $\ldots$ & 0 & $b_{2}$ \\
\hline$\ldots$ & 0 & $\ldots$ & $\ldots$ & $\ldots$ & $\ldots$ & $\ldots$ & $\ldots$ & $\ldots$ & $\ldots$ & $\ldots$ \\
\hline$\ldots$ & 0 & $\ldots$ & $\ldots$ & $\ldots$ & $\ldots$ & $\ldots$ & $\ldots$ & $\ldots$ & $\ldots$ & $\ldots$ \\
\hline$\ldots$ & 0 & $\ldots$ & $\ldots$ & $\ldots$ & $\ldots$ & $\ldots$ & $\ldots$ & $\ldots$ & $\ldots$ & $\ldots$ \\
\hline$S_{n}$ & 0 & $a_{m 1}$ & $a_{m 2}$ & $\ldots$ & $a_{m n}$ & 0 & 0 & $\ldots$ & 1 & $b_{m}$ \\
\hline
\end{tabular}

Tabel 1. Tabel Awal Simpleks

Keterangan: $C_{n}=$ nilai koefisien keuntungan per-bungkus produk untuk setiap $x_{n}$

$x_{n}=$ variabel keputusan ke-n

$s_{n}=$ variabel slack ke-n

$a_{(m n)}=$ kebutuhan sumber daya $\mathrm{m}$ untuk setiap $x_{n}$

$b_{m}=$ jumlah sumber daya yang tersedia 


\section{Metode Penelitian}

\section{Metode Pengumpulan Data}

Dalam penulisan ilmiah ini, menggunakan beberapa cara dalam pengumpulan data yaitu :

(a) Studi Lapangan

- Pengamatan (Observasi) adalah suatu cara mendapatkan informasi secara langsung dengan melakukan peninjauan ke Perusahaan Keripik Balado Mahkota

- Wawancara (Interview) yaitu dengan cara mengadakan tanya jawab secara langsung dengan pemilik dan karyawan perusahaan.

(b) Studi Pustaka

Studi pustaka dilakukan dengan mempelajari buku-buku yang berhubungan dengan permasalahan yang akan dibahas. Teori dasar yang digunakan adalah Metode simpleks dan analisa sensitivitas untuk mengetahui bagaimana cara penyelesaian persoalan dan perhitungan pada permasalahan yang ada pada perusahaan Keripik Balado Mahkota.

\section{Metode Analisis Data}

Metode Analisis Data yang digunakan dalam penulisan ilmiah ini adalah pemrograman linear dengan metode simpleks dan dibantu paket software QSB (Quantitative System for Business) dengan langkah-langkah berikut:

(a) Membuat Variabel dengan Beberapa Kendala atau Constraint Jika produk yang dibutuhkan sudah dapat yaitu keripik balado dengan jenis keripik balado bulat $\mathrm{kg}$, keripik balado bulat $\mathrm{kg}$, keripik balado panjang $\mathrm{kg}$, keripik balado panjang $\mathrm{kg}$, maka produk tersebut dijadikan variabel fungsi tujuan untuk memudahkan perhitungan metode simplek.

- Mencari beberapa kendala dari produk keripik balado Jika dari pengamatan yang ada maka, kendala yang akan diperhitungkan adalah ubi kayu bulat, ubi kayu panjang, bumbu-bumbu, minyak goreng, minyak solar, dan jam tenaga kerja yang digunakan. Pada dasarnya perhitungan pemrograman linier ini fungsi tujuannya yaitu memaksimalkan keuntungan total dari tiap produk.

(b) Memaksimalkan Kendala untuk memperoleh Keuntungan Optimal Pada fungsi tujuan ini untuk menyelesaikan persoalan pemrograman linier dengan memperhatikan kendala-kendala yang ada. Biasanya kendalakendala yang ada tersebut meliputi material atau bahan baku dan waktu tenaga kerja sebagai inputnya, dan output yang nantinya akan keluar disetiap variabel atau produk tersebut berupa angka yang satuannya bungkus.

(c) Menghitung dengan Perhitungan Iterasi (hitungan perulangan) Sampai Hasil Optimal Pada fungsi tujuan ini untuk menyelesaikan persoalan Pemrograman linier ini dilakukan jika perhitungannya ditambahkan dengan (negatif) dan nilai $\mathrm{Z}$ nantinya tidak ada lagi nilai negatif maka artinya perhitungan tersebut telah optimal.

(d) Menganalisa Solusi yang diperoleh Dalam menganalisah data awal kita dapat melihat hasil produk tiap bungkus dan mengetahui berapa solusi optimal yang dicapai. apakah nilai penyelesaian secara manual sama dengan penyelesaian yang menggunakan program QSB. Uji sensitivitas dilakukan untuk menentukan pengaruh perubahan data, variabel atau kendala pada model terhadap keputusan optimal yang didapat. 


\section{Pembahasan}

Untuk mempermudah dalam hal perhitungan metode simpleks, data yang telah diperoleh kita ubah dalam bentuk umum pemrograman linier.Langkah-langkah awal yang harus ditentukan terlebih dahulu adalah dengan menentukan tiga faktor utama, yaitu:

1. Variabel keputusan

Produk keripik balado apa saja yang akan diproduksi dan berapa jumlah bungkus yang akan diproduksi dalam satu hari kerja.

2. Fungsi tujuan memaksimalkan keuntungan.

$$
Z=7408,311 x_{1}+2788,363 x_{2}+7579,313 x_{3}+2913,863 x_{4}
$$

dimana : $Z=$ Jumlah keuntungan seluruh produk $x_{1}=$ Keripik balado bulat $\frac{1}{2} \operatorname{kg} x_{2}=$ Keripik balado bulat $\frac{1}{4} \operatorname{kg} x_{3}=$ Keripik balado panjang $\frac{1}{2} \operatorname{kg} x_{4}$ $=$ Keripik balado panjang $\frac{1}{4} \mathrm{~kg}$

3. Fungsi kendala

Batasan-batasan dalam mencapai tujuan.

$$
\begin{aligned}
0,485 x_{1}+0,242 x_{2}+0 x_{3}+0 x_{4} & \leq 135 \\
0 x_{1}+0 x_{2}+0,485 x_{3}+0,242 x_{4} & \leq 200 \\
0,09 x_{1}+0,045 x_{2}+0,09 x_{3}+0,045 x_{4} & \leq 67 \\
0,17 x_{1}+0,08 x_{2}+0,17 x_{3}+0,08 x_{4} & \leq 134 \\
0,125 x_{1}+0,063 x_{2}+0,125 x_{3}+0,063 x_{4} & \leq 95 \\
0,21 x_{1}+0,105 x_{2}+0,21 x_{3}+0,105 x_{4} & \leq 160
\end{aligned}
$$

dimana: $x_{1}, x_{2}, x_{3}, x_{4} \geq 0$ Setelah kita modelkan kedalam bentuk model pemrograman linier, maka kita dapat menyelesaikannya secara manual maupun bantuan software QSB. Dengan penghitungan sampai memperoleh solusi untuk keuntungan maksimal.

(a) Penyelesaian Secara Manual Langkah-langkah untuk mencari solusi optimal dari permasalahan optimalisasi keuntungan pada keripik balado mahkota adalah sebagai berikut:

- Mengubah fungsi tujuan dan fungsi kendala

- Menyusun persamaan-persamaan di dalam tabel awal simpleks pada Tabel 1

\begin{tabular}{|c|c|c|c|c|c|c|c|c|c|c|c|c|}
\hline$V b$ & $Z$ & $x_{1}$ & $x_{2}$ & $x_{3}$ & $x_{4}$ & $S_{1}$ & $S_{2}$ & $S_{3}$ & $S_{4}$ & $S_{5}$ & $S_{6}$ & $N K$ \\
\hline$Z$ & 1 & $-7408,31$ & $-2788,36$ & $-7579,31$ & $-2913,83$ & 0 & 0 & 0 & 0 & 0 & 0 & 0 \\
\hline$S_{1}$ & 0 & 0,485 & 0,242 & 0 & 0 & 1 & 0 & 0 & 0 & 0 & 0 & 135 \\
\hline$S_{2}$ & 0 & 0 & 0 & 0,485 & 0,242 & 0 & 1 & 0 & 0 & 0 & 0 & 200 \\
\hline$S_{3}$ & 0 & 0,09 & 0,045 & 0,09 & 0,045 & 0 & 0 & 1 & 0 & 0 & 0 & 67 \\
\hline$S_{4}$ & 0 & 0,17 & 0,08 & 0,17 & 0,08 & 0 & 0 & 0 & 1 & 0 & 0 & 134 \\
\hline$S_{5}$ & 0 & 0,125 & 0,063 & 0,125 & 0,063 & 0 & 0 & 0 & 0 & 1 & 0 & 95 \\
\hline$S_{6}$ & 0 & 0,21 & 0,105 & 0,21 & 0,105 & 0 & 0 & 0 & 0 & 0 & 1 & 160 \\
\hline
\end{tabular}

Tabel 2. Tabel Awal Simpleks 
- Memilih kolom kunci

- Memilih baris kunci

- Mengubah nilai-nilai baris kunci

- Mengubah nilai-nilai selain pada baris kunci

Berdasarkan perhitungan pada iterasi pertama diperoleh tabel baru simpleks dengan nilai baru.

\begin{tabular}{|c|c|c|c|c|c|c|c|c|c|c|c|c|}
\hline$V b$ & $Z$ & $x_{1}$ & $x_{2}$ & $x_{3}$ & $x_{4}$ & $S_{1}$ & $S_{2}$ & $S_{3}$ & $S_{4}$ & $S_{5}$ & $S_{6}$ & $N K$ \\
\hline$Z$ & 1 & 0 & 907,64 & 0 & 867,98 & 15270,01 & 15627,78 & 0 & 0 & 0 & 0 & 5187597,085 \\
\hline$X_{1}$ & 0 & 1 & 0,4989 & 0 & 0 & 2,0612 & 0 & 0 & 0 & 0 & 0 & 278,35 \\
\hline$X_{3}$ & 0 & 0 & 0 & 1 & 0,498 & 0 & 2,061 & 0 & 0 & 0 & 0 & 412,371 \\
\hline$S_{3}$ & 0 & 0 & 0,00009 & 0 & 0,00009 & $-0,1855$ & $-0,185$ & 1 & 0 & 0 & 0 & 4,835 \\
\hline$S_{4}$ & 0 & 0 & $-0,00481$ & 0 & $-0,0048$ & $-0,3504$ & $-0,35$ & 0 & 1 & 0 & 0 & 16,577 \\
\hline$S_{5}$ & 0 & 0 & 0,00063 & 0 & 0,00062 & $-0,2576$ & $-0,257$ & 0 & 0 & 1 & 0 & 8,659 \\
\hline$S_{6}$ & 0 & 0 & 0,00023 & 0 & 0,00021 & $-0,4329$ & $-0,433$ & 0 & 0 & 0 & 1 & 14,9485 \\
\hline
\end{tabular}

Tabel 3. Tabel Optimal Simpleks

- Melanjutkan perbaikan

Ulangilah langkah-langkah perbaikan mulai langkah 3 sampai langkah ke-6 untuk memperbaiki tabel-tabel yang telah diubah atau diperbaiki nilainya. Perubahan baru berhenti setelah pada baris pertama (fungsi tujuan) tidak ada yang bernilai negatif. Dari Tabel 2 maka diperoleh:

i. Solusi Optimal

$$
\begin{gathered}
x_{1}=278,35 \\
x_{3}=412,371 \\
x_{2} \operatorname{dan} x_{4}=0 \\
\mathrm{Z}=5187597,085
\end{gathered}
$$

Dalam uraian diatas artinya untuk memperoleh keuntungan maksimum sebesar Rp 5.187.597,085 maka perusahaan Keripik Balado Mahkota sebaiknya menghasilkan produk $X_{1}$ sebanyak 278 bungkus dan produk $X_{3}$ sebanyak 412 bungkus.

ii. Status sumber daya

- $S_{3}=4,835$ (satuan kilogram) sumber daya minyak goreng berlebih.

- $S_{4}=16,577$ (satuan kilogram) sumber daya bumbu-bumbu berlebih.

- $S_{5}=8,659$ (satuan liter) sumber daya minyak solar berlebih.

- $S_{6}=14,9485$ (satuan jam) sumber daya jam tenaga kerja berlebih.

- $S_{1}=S 2=0$. Kedua sumber daya ubi kayu bulat dan ubi kayu panjang habis terpakai .

\section{Kesimpulan}

Keuntungan optimal yang diperoleh Perusahaan Keripik Balado Mahkota apabila menggunakan perhitungan secara manual dan bantuan software QSB (Quantitative System for Business) adalah Rp. 5.187.596 dengan memfokuskan pro- 
duksi pada keripik balado bulat $\frac{1}{2} \mathrm{~kg}\left(x_{1}\right)$ sebanyak 278 bungkus dan keripik balado panjang $\frac{1}{2} \mathrm{~kg}\left(x_{3}\right)$ sebanyak 412 bungkus. Hasil uji sensitivitas QSB (Quantitative System for Business) dapat menjelaskan faktor-faktor yang menyebabkan produksi yang tidak optimal dan keuntungan tidak maksimal yaitu berlebihnya sumber daya yang disediakan dimana $S_{3}=4,83 \mathrm{~kg}$ (minyak goreng), $S_{4}=16,57$ $\mathrm{kg}$ (bumbu-bumbu), $S_{5}=8,6597967$ liter (minyak solar) dan $S_{6}=14,94$ jam (waktu tenaga kerja). Sumber daya yang berlebih dapat ditolerir perubahannya dengan meningkatkan sumber daya persediaan untuk $S_{1}=161,0556 \mathrm{~kg}$ (ubi kayu bulat) dan $S_{2}=226,0556 \mathrm{~kg}$ (ubi kayu panjang), dengan meningkatkan persediaan sumber daya $S_{1}$ dan $S_{2}$ dapat meminimalisir sumber-sumber daya yang berlebih pada $S_{3}, S_{4}, S_{5}$ dan $S_{6}$.

\section{Ucapan Terima Kasih}

Penulis mengucapkan terima kasih kepada Bapak Budi Rudianto, Bapak Dodi Devianto, Ibu Hazmira Yozza, Bapak Effendi dan Bapak Narwen atas bimbingan, kritik dan saran sehingga tulisan ini dapat dirampungkan.

\section{Daftar Pustaka}

1. Dimyati, T.T. dan A. Dimyati. 2006. Operations Research Model-model Pengambilan Keputusan. Sinar Baru Algensindo, Bandung

2. Lusiana. 2006. Penyelesaian Program Linier dengan Metode Simpleks. Skripsi S-1 Metematika UNAND, tidak diterbitkan.

3. Subagyo, P., M. Asri., dan T.H. Handoko. 2004. Dasar-dasar Operations Research. BPFE, Yogyakarta 